\title{
Beyond Tropical Storms: Understanding Disturbance and Forest Dynamics
}

\section{OPEN ACCESS}

Edited by:

Barry Alan Gardiner, Institut Européen De La Forêt Cultivée

(IEFC), France

Reviewed by:

Allan L. Carroll,

University of British Columbia,

Canada

Yi-Ying Chen,

Academia Sinica, Taiwan

${ }^{*}$ Correspondence:

Tamara Heartsill-Scalley

tamara.heartsill-scalley@usda.gov

Specialty section:

This article was submitted to

Forest Disturbance

a section of the journal

Frontiers in Forests and Global

Change

Received: 22 April 2021

Accepted: 15 July 2021

Published: 04 August 2021

Citation:

Heartsill-Scalley $T$ and López-Marrero T (2021) Beyond Tropical Storms: Understanding

Disturbance and Forest Dynamics.

Front. For. Glob. Change 4:698733.

doi: 10.3389/ffgc.2021.698733

\begin{abstract}
Tamara Heartsill-Scalley ${ }^{*}$ and Tania López-Marrero ${ }^{2}$
${ }^{1}$ USDA Forest Service, International Institute of Tropical Forestry, Río Piedras, Puerto Rico, ${ }^{2}$ Department of Social Sciences and Interdisciplinary Center for Coastal Studies, University of Puerto Rico, Mayagüez Campus, Mayagüez, Puerto Rico
\end{abstract}

Most of the knowledge of tropical storm effects on forests is from studies conducted in reserves and protected areas. Effects on other settings such as urban forests, coastal forests, and in landscapes with mixed land uses and covers are, comparatively, less studied. Yet research from a range of forest types and landscape compositions is needed to inform actions associated with management, mitigation, or restoration efforts before and after storms. Studies of forests comprising various conditions, along with long-term observations, would offer unique insights into the varied and cumulative effects of tropical storms on forest ecosystems. The Caribbean island of Puerto Rico is one of the sites where most tropical storm-forest studies are conducted, yet studies come from a limited set of sites. Using Puerto Rico as a case study, we emphasize the need for broader research approaches that represent the wider range of forests that are exposed to tropical storms. Such an approach will provide valuable knowledge and understanding needed to inform and take actions across landscape settings, forest context, and socio-environmental conditions.

Keywords: forest disturbance, tropical storms, land use/land cover change, forest type, landscape setting, environmental history, interdisciplinary research, Puerto Rico

\section{INTRODUCTION}

Tropical storms not only affect forests directly, but also the services and benefits they provide to sustain human wellbeing and their associated ecological, social, and technological systems (Chang et al., 2018; Lugo, 2020). Effects of storms on forests can be drastic or minimal in appearance, immediate or long lasting (Lugo, 2008; Schowalter et al., 2021). The breadth of topics included in research on the effects of storms on forests spans forest structure, root dynamics, species composition and diversity, as well as ecosystem functions (Shiels et al., 2014; McLaren et al., 2019; Uriarte et al., 2019; Yaffar and Norby, 2020). The increasing importance of research on storms and forests has been the topic of various recent review articles (Xi, 2015; Ibanez et al., 2019; Pruitt et al., 2019; Hogan et al., 2020; Lin et al., 2020).

Recent climate projections for the Caribbean Basin predict stronger cyclonic events by the end of the century (Bender et al., 2010; Balaguru et al., 2020). These projections include increases in storm 
surges, maximum wind speeds, and rainfall from tropical storm events (Torres and Tsimplis, 2014; McLean et al., 2015; StennettBrown et al., 2017; Martínez et al., 2019; Climate Studies Group Mona, 2020). Tropical storms and their effects on forests are studied worldwide, with the Caribbean and wider Atlantic Basin having more studies relative to other parts of the planet exposed to cyclones (Lin et al., 2020). In fact, a large proportion of published research on storms and forests is conducted in Puerto Rico, with only a few research sites contributing the most studies (López-Marrero et al., 2019; Lin et al., 2020). Therefore, not all forest types and conditions exposed to storm effects are adequately represented in current research.

The complexities of research on forests and tropical storms are the basis of recent calls to action and reviews aimed at promoting consistent data collection before the disturbance event, the use of similar protocols, and common research agendas across sites (Xi, 2015; Pruitt et al., 2019; Hogan et al., 2020; Lin et al., 2020). These reviews of storms and forest research also highlight the importance of before and after measurements to avoid confounding factors in the interpretation of storm effects. These reviews, however, are focused on improving methods and practices in existing or ongoing study sites. We note that the importance of broadening the types and conditions of forest studied is missing from these recent reviews aimed at advancing the studies on storms and forests. If the aim is to generate knowledge on the effects of storms and forests to inform actions to enhance resilience, then increasing studies in a range of landscapes and forest contexts is needed. When interpreting results, it is important to consider where research is being conducted and how representative of the broader forest context and landscape condition a research site may be (Fahey et al., 2015).

In this perspective article, we seek to highlight the importance of forest context and landscape setting in studies of tropical storms and forests. For the purpose of this article, "forest context" encompasses components and environmental conditions of forests being studied (climatic conditions, forest structure and composition, forest substrate, previous disturbances, intensity of storm effect, and cumulative effects of recurrent storms and other disturbances) while "landscape setting" refers to the matrix of landscape surrounding the studied forests (for example, "forest surrounded by forest" as opposed to forest surrounded by- or in a matrix of- mixed land covers) and current and past human activity influencing forests and its surrounding lands. We use Puerto Rico as a case study to emphasize the need for a broader landscape-context approach on the study of tropical storm disturbances in forests, as most studies are currently conducted in a limited set of sites and under settings that do not represent the most common types and conditions of forests in the landscape. To sustain and exemplify our argument, we provide a synopsis of published ecological research on the topic of tropical storms and forests in Puerto Rico (section "Synopsis of Ecological Research on Tropical Storms and Forests in Puerto Rico"), followed by examples of research where observations of storm effects varied depending on forest context and landscape setting (section "Forest Context and Landscape Settings in the Study of Tropical Storms and
Forests in Puerto Rico: Some Examples"). We present concluding remarks on the need for research that addresses a broader representation of forests in order to move forward our knowledge and understanding of tropical storm effects on forest ecosystems (section "Concluding Remarks: Seeking Broader Representation of Forests and Landscapes").

\section{SYNOPSIS OF ECOLOGICAL RESEARCH ON TROPICAL STORMS AND FORESTS IN PUERTO RICO}

From 1900 to 2020, a total of 75 tropical storms passed over or within $138 \mathrm{~km}$ of Puerto Rico's coasts (following López-Marrero and Castro-Rivera, 2020). Passage of these atmospheric systems, ranging in intensity and trajectory, has provided opportunities to conduct research on disturbance effects on forest ecosystems and to produce new knowledge to broaden understanding of storms and forests in Puerto Rico and elsewhere. The prolific, long-term tropical storm and forest research in Puerto Rico is recognized for its contributions to tropical forest knowledge and is referenced worldwide (e.g., Burslem et al., 2000; Sato, 2004; Mascaro et al., 2005; Imbert and Portecop, 2008; Gleason et al., 2010; Lin et al., 2011, 2020; Luke et al., 2016; Yap et al., 2016).

A systematic literature review conducted by López-Marrero et al. (2019), identified 166 peer-reviewed research articles published between 1900 and 2017 regarding the study of tropical storms and forests in Puerto Rico. Most of these articles (85\%) assessed storm effects on the biotic component of forest ecosystems, particularly plants, and mostly trees. Fewer studies (25\% of plant-focused articles) addressed effects on a combination of plant life forms or assessed combined effects of storms and other aspects of biotic or abiotic forest ecosystem components (22\% of plant-focused articles). When the biotic component was animals (37\% of all articles), most of the studies (96\% of animal-focused articles) researched an animal taxa individually; fewer studies addressed different taxa of animals in conjunction with, or including the interactive effects of, other organisms and processes. Moreover, most articles discuss the sole effects of storms on biotic components, as opposed to exploring the effects in relation to other disturbances or as part of land-use and land-cover change (e.g., past hurricanes, droughts, landslides, selective harvesting, land conversion).

López-Marrero et al. (2019) document that most of the knowledge on storm effects in Puerto Rico's forests is from studies in protected areas, particularly the Luquillo Experimental Forest (LEF) in northeastern Puerto Rico where $86 \%$ of the studies were conducted. Research from study sites in protected areas tends to occur in a landscape of forested lands ("forest surrounded by forest"), as opposed to forests surrounded by other land covers. Moreover, most studies (91\%) were conducted in a forest context of wet/humid climatic zones (where LEF is located) and focusing on only one climatic zone, instead of comparing effects between zones. Some studies, albeit fewer, were conducted in other protected forest areas, in landscape settings 
representative of other climatic conditions and geographic locations, for example, in Guánica Commonwealth Forest (dry) and Cambalache Commonwealth Forest (moist/wet). Few studies addressed coastal forest contexts, either mangroves or other forested wetlands. In terms of studied tropical storms, Hurricanes Hugo (1989) and Georges (1998) were the most studied. Hurricane Hugo was the focus of study in $65 \%$ of the articles, while Hurricane Georges was the focus of study in $40 \%$. In more than half of those publications, storm events were studied individually; few studies addressed the interactive and cumulative effects of two or more storms in forest ecosystems. Most of the published research consisted of multiannual data collections with two or more years of study duration.

We updated the systematic literature review conducted by López-Marrero et al. (2019) after the hurricane season of 2017 when Puerto Rico was affected by hurricanes Irma and María and identified 18 additional articles published between 2018 and 2020 assessing ecological effects of storms on forests. Of those articles, 13 addressed the effects of hurricanes Irma and María. Analysis of those articles revealed that, like in the 1990-2017 study period, most of this recent research focused on studies about biotic components of the forest ecosystem, and many, specifically on trees. Likewise, the LEF was the study site for most of these articles. However, there was relatively more research conducted in multiple study sites, allowing for comparisons of hurricane effects on different landscape settings and forest contexts. Finally, we found that in the reviewed period of 20182020 only two articles compared the effects of three hurricanes (Hugo, Georges, and María).

\section{FOREST CONTEXT AND LANDSCAPE SETTINGS IN THE STUDY OF TROPICAL STORMS AND FORESTS IN PUERTO RICO: SOME EXAMPLES}

The research on tropical storms and forests in Puerto Rico currently provides limited representation of forest types, contexts, and landscape settings. Current knowledge is mostly based on research from protected forests within forested landscapes, mostly in mountainous, and in wet zones (LópezMarrero et al., 2019). Indeed, forest reserves and long-term research sites are fundamental to the understanding of forests and storms with an essential role as drivers of knowledge generation (Zimmerman et al., 2021).

From research conducted within a forested landscape setting in a wet montane forest we have learned that the biotic component of tree aboveground biomass after Hurricane Hugo was reduced by $50 \%$ yet recovered to baseline levels within 10 years (Heartsill-Scalley et al., 2010). Tree biomass recovered, and species composition increased beyond prehurricane conditions after 15 years of observations. In the same study area, and in contrast to trees, non-tree vegetation such as ferns and vines were observed to recover quickly but decrease in species richness after the same hurricane.
Because understory and non-tree vegetation comprise the bulk of forest plant diversity, and understory vegetation serves to filter recruitment of tree seedlings, these findings are significant for understanding further changes associated to storm effects on forests. Studies of non-tree vegetation and hurricanes have been conducted in only a few landscape settings, including forests in agricultural landscapes (Perfecto et al., 2019) and forests surrounded by forests (MeléndezAckerman et al., 2003; Royo et al., 2011). We do not know enough about how storms affect non-tree vegetation in a range of forest contexts and landscape settings. Non-tree vegetation plays important roles in both human livelihoods and forest succession dynamics, as these plants may allocate more resources to roots, re-sprout leaves or fronds, flowering, and fruiting in the post-hurricane forest, thus providing resources for a range of consumers and uses and contributing to increase forest biomass (Wunderle, 1999; Meléndez-Ackerman et al., 2003; Royo et al., 2011; Pagán-Jiménez et al., 2019; Soto-Parrilla and Heartsill-Scalley, 2021).

Ecosystem processes occurring within the same landscape setting of "forest surrounded by a forests", range in temporal scales and in their recovery. For instance, leaf-fall and movement of leaves through forest streams recover at different time ranges, taking from months to decades to return to pre-hurricane conditions. In the same study site it only took 5 years for leaf-fall rates to return to pre-hurricane Hugo levels, while for the movement and export of leaves via forest streams takes more than 20 years to recover (Heartsill-Scalley et al., 2012). These differences in effects and recovery intervals demonstrate that ecosystem processes are complex and dependent on a combination of forest structure, species composition, and intensity of storm effects. As pointed out by Lin et al. (2020), long-term studies and observations at different time scales, both prior to and after disturbance events, are fundamental. Beyond these long-term studies and addressing different time scales, we also note the need to explore the potential cumulative and synergistic effects of recurring disturbances through time on forest ecosystems.

We must also keep in mind how representative research sites in forested landscape settings may or may not be, and what are the challenges to their applicability to broader forest contexts and landscape settings (Fahey et al., 2015). For instance, and although forests in urban landscapes are also affected by tropical storms, these currently do not represent a large proportion of published research on forests and storms. Nevertheless, urban areas are expanding rapidly, resulting often in a sprawling landscape that may surround and contain a range of urban forests that are either remnants of historical forest distributions or are urban forests with novel species composition (Lugo et al., 2012, 2020).

Within an urbanized landscape setting, there are significant distinctions in urban forest context, whether historical remnant or novel, and both still are underrepresented in studies of storm effects. Increasing the number of studies and the understanding of storm effects on forests in urban areas has, however, challenges. For example, constraints identified in urban forest recovery and succession (such as landscape seed 
sources or source-and-sink metapopulation dynamics) become strained with higher landscape urbanization levels and urban sprawl (Yu et al., 2019). These conditions associated with urban forest fragmentation are understudied in both upland forests and coastal forest wetlands. Moreover, and beside storm events, other processes and dynamics in urban areas affect coastal forests, potentially reducing the services and diminishing their natural regeneration capacity. The forest context in this urban landscape setting must consider, consequently, a combination of disturbances in coastal areas such as urban encroachment, hydrological modifications, sea-level rise, floods, or storm surges (Branoff, 2019; Yu et al., 2019; Yu and Gao, 2020). Moreover, forest context in coastal urban settings includes a variety of conditions such as dry forest over karst substrates, mangroves, novel forests, and other brackish and freshwater wetlands. Under such a range of forest contexts, exploring the potential compounding effects of storms and other disturbances including (including human activity), as well as forest conditions, is needed.

Forest context and landscape setting are a product of environmental history and human influence. This includes, for example, a combination of previous land use and human activity, previous disturbances (droughts, storms, landslides), and presence of particular species or other forest elements at a study site. Therefore, environmental history and human activity of a forest site is an important lens through which to interpret the effects of tropical storm disturbances on forests and their subsequent successional trajectories. Awareness of historical forest context and landscape settings not only serves to estimate the age of forest stands, but also the changes in the surrounding forest. The degree to which tropical storms may alter structure and species composition in a forest site is, in part, a consequence of the template left by past land use and human activity (Fu et al., 1996; Foster et al., 1999; Lomáscolo and Aide, 2001). Previous land-use history is consistently found to be a driver of species composition and successional trajectories beyond the effects from storms in forested landscapes (Hogan et al., 2016, 2017). Although hurricanes alter structure and species composition, they do so over a landscape influenced by enduring past human uses and management activities, and consequently, acting upon multiple cumulative, and interacting disturbances.

Multiple and interacting disturbances influence the type of effects and the range of responses of forests to tropical storms. For instance, a hurricane followed by drought would need different threshold indicators for management actions than storms followed by heavy rainfall and floods. In a study that encompassed various forest contexts within the same "forest surrounded by forest" landscape setting, Campos-Cerqueira and Aide (2021) incorporate pre-existing knowledge of drought and hurricane responses in their long-term analyses of fauna. They identified that the drought preceding Hurricane María had stronger effects on their fauna observation than the hurricane did. Therefore, they were able to properly interpret observations of post-hurricane effects by explicitly integrating multiple and previous disturbances into their analyses. Yu and Gao (2020) also incorporated hurricane and drought in a study of forests within various forested landscape settings: lowland forested wetland, montane wet forests, and coastal dry forests. They were able to identify factors such as orientation, topography, and elevation that, in addition to the drought, were associated to each forest context's level of hurricane effects, tree structure changes, and recovery response rates. In mangroves and coastal forested wetlands, effects of storm surges are often integrated and hard to distinguish from the hurricane event. Therefore, being able to identify structural damage from wind and mortality from storm surge flooding are important when proposing management actions to restore affected coastal forests. An approach that considers studying separate and combined effects of both storm surge flooding and canopy foliage loss from hurricane winds is needed, both in forested and urbanized landscape settings. This would more efficiently guide management actions for coastal area forests, which may include the need for surface and hydrological modifications before vegetation restoration and tree planting activities (Branoff, 2019; Yu et al., 2019). Studies such as Campos-Cerqueira and Aide (2021) and Yu and Gao (2020) demonstrate the need to address and increase our knowledge of the effects and feedbacks of multiple disturbances in forest ecosystems, as well as in settings outside of forested landscapes.

\section{CONCLUDING REMARKS: SEEKING BROADER REPRESENTATION OF FORESTS AND LANDSCAPES}

Building knowledge on the effects of tropical storm disturbances on forest dynamics requires an approach that is broadly representative. The goal of this article is to promote production of new knowledge on- and understanding of tropical storms and forests that encompasses a wide range of forest contexts and landscape settings affected by such events. To advance knowledge applicable to all forest types and contexts areas that are exposed to cyclonic activity, we must explicitly study forests in a variety of landscape setting and contexts: coastal, dry, urban, novel, among others. Moreover, resource managers and the broader community seek to develop plans to implement actions before and after storms in community forests, agroforestry systems, urban, and suburban interface areas (Imbert, 2018; Lazos-Chavero et al., 2018; Perfecto et al., 2019; Landry et al., 2021; Rodríguez-Cruz and Niles, 2021; Torres-Martínez et al., 2021) and they often need to decide on priorities for management actions in multiple forest contexts and landscape settings. Consequently, understanding forest effects, processes, and subsequent response and recovery time scales in a variety of contexts and settings can serve to guide decision-making and management actions needed to build resilience in the ecological, social, and technological systems in which forest are embedded.

Current climate change projections of tropical storm activity place us at a threshold moment where research on a broader set of forest contexts and in different landscape settings is required to facilitate management, mitigation, or restoration efforts. To address the complex effects of tropical storms on forest ecosystems, inputs from various disciplines is required. Actions 
to maintain forest cover, along with the services and benefits they provide, must consider their applicability throughout the complex landscape mosaics affected by tropical storms; it should be explored through the lens and collaboration of multiple disciplines. Enhancing our knowledge on hurricanes and forests as broadly as possible will improve our capacity to live with tropical storms and changing socio-environmental conditions.

\section{DATA AVAILABILITY STATEMENT}

The original contributions presented in the study are included in the article/supplementary material, further inquiries can be directed to the corresponding author.

\section{AUTHOR CONTRIBUTIONS}

TH-S and TL-M contributed equally to manuscript conceptualization and development. TH-S led writing. Both authors revised and agreed on final content of the manuscript.

\section{REFERENCES}

Balaguru, K., Foltz, G. R., Leung, L. R., Kaplan, J., Xu, W., Reul, N., et al. (2020). Pronounced impact of salinity on rapidly intensifying tropical cyclones. Bull. Am. Meteorol. Soc. 101, E1497-E1511.

Bender, M. A., Knutson, T. R., Tuleya, R. E., Sirutis, J. J., Vecchi, G. A., Garner, S. T., et al. (2010). Modeled Impact of Anthropogenic Warming on the Frequency of Intense Atlantic Hurricanes. Science 327, 454-458. doi: 10.1126/science. 1180568

Branoff, B. (2019). Mangrove Disturbance and Response Following the 2017 Hurricane Season in Puerto Rico. Estuaries Coast. 43, 1248-1262. doi: 10.1007/ s12237-019-00585-3

Burslem, D. F., Whitmore, T. C., and Brown, G. C. (2000). Short-term effects of cyclone impact and long-term recovery of tropical rain forest on Kolombangara, Solomon Island. J. Ecol. 88, 1063-1078. doi: 10.1046/j.13652745.2000.00517.x

Campos-Cerqueira, M., and Aide, T. M. (2021). Impacts of a drought and hurricane on tropical bird and frog distributions. Ecosphere 12:e03352.

Chang, C. T., Vadeboncoeur, M. A., and Lin, T. C. (2018). Resistance and resilience of social-ecological systems to recurrent typhoon disturbance on a subtropical island: Taiwan. Ecosphere 9"e02071.

Climate Studies Group Mona (2020). The State of the Caribbean Climate. Kingston: University of the West Indies. 200.

Fahey, T. J., Templer, P. H., Anderson, B. T., Battles, J. J., Campbell, J. L., Driscoll, C. T., et al. (2015). The promise and peril of intensive-site-based ecological research: Insights from the Hubbard Brook ecosystem study. Ecology 96, 885-901. doi: 10.1890/14-1043.1

Foster, D. R., Fluet, M., and Boose, E. R. (1999). Human or natural disturbance: Landscape-scale dynamics of the tropical forests of Puerto Rico. Ecol. Appl. 9, 555-572. doi: 10.1890/1051-0761(1999)009[0555:hondls]2.0.co;2

Fu, S. L., Pedraza, C. R., and Lugo, A. E. (1996). A twelve-year comparison of stand changes in a mahogany plantation and a paired natural forest of similar age. Biotropica 28, 515-524. doi: 10.2307/2389093

Gleason, S. M., Read, J., Ares, A., and Metcalfe, D. J. (2010). Species-soil associations, disturbance, and nutrient cycling in an Australian tropical rainforest. Oecologia 162, 1047-1058. doi: 10.1007/s00442-009-1527-2

Heartsill-Scalley, T., Scatena, F. N., Lugo, A. E., Moya, S., and Estrada Ruiz, C. R. (2010). Changes in structure, composition, and nutrients during 15 years of hurricane-induced succession in a subtropical wet forest. Biotropica 42, 455-463. doi: 10.1111/j.1744-7429.2009. 00609.x

\section{FUNDING}

USDA Forest Service IITF and UPR Mayagüez provided salary to authors.

\section{ACKNOWLEDGMENTS}

Research at the International Institute of Tropical Forestry, USDA Forest Service (FS) is done in collaboration with the University of Puerto Rico (UPR). We thank Carlos F. Rivera-López (Harvard University) and the staff at the library of the USDA Forest Service, International Institute of Tropical Forestry (Jorge Morales and Evelyn Pagán) for facilitating publications for the scientific literature synopsis revision, Tamara L. Enz for revising an early manuscript draft, and Ariel E. Lugo and two reviewers for their comments and suggestions. The findings, conclusion, and views expressed in this manuscript are those of the authors and do not necessarily represent the views of the USDA FS nor the UPR.

Heartsill-Scalley, T., Scatena, F. N., Moya, S., and Lugo, A. E. (2012). Long-term dynamics of organic matter and elements exported as coarse particulates from two Caribbean montane watersheds. J. Trop. Ecol. 28, 127-139. doi: 10.1017/ s0266467411000733

Hogan, J. A., Feagin, R. A., Starr, G. G., Ross, M. T., Lin, C., O’Connell, C., et al. (2020). A Research Framework to Integrate Cross-Ecosystem Responses to Tropical Cyclones. Bioscience 70, 477-489.

Hogan, J. A., Mayorquin, S., Rice, K., Thompson, J., Zimmerman, J. K., and Brokaw, B. (2017). Liana dynamics reflect land-use history and hurricane response in a Puerto Rican forest. J. Trop. Ecol. 33:155. doi: 10.1017/ s0266467417000049

Hogan, J. A., Zimmerman, J. K., Thompson, J., Nytch, C. J., and Uriarte, M. (2016). The interaction of land-use legacies and hurricane disturbance in subtropical wet forest: Twenty-one years of change. Ecosphere 7:e01405.

Ibanez, T., Keppel, G., Menkes, C., Gillespie, T. W., Lengaigne, M., Mangeas, M., et al. (2019). Globally consistent impact of tropical cyclones on the structure of tropical and subtropical forests. J. Ecol. 107, 279-292. doi: 10.1111/1365-2745. 13039

Imbert, D. (2018). Hurricane disturbance and forest dynamics in east Caribbean mangroves. Ecosphere 9:e02231. doi: 10.1002/ecs2.2231

Imbert, D., and Portecop, J. (2008). Hurricane disturbance and forest resilience: Assessing structural vs. functional changes in a Caribbean dry forest. For. Ecol. Manag. 255, 3494-3501. doi: 10.1016/j.foreco.2008.02.030

Landry, S. M., Koeser, A. K., Kane, B., Hilbert, D. R., McLean, D. C., Andreu, M., et al. (2021). Urban forest response to Hurricane Irma: The role of landscape characteristics and sociodemographic context. Urban For. Urban Green. 61, 127093. doi: 10.1016/j.ufug.2021.127093

Lazos-Chavero, E., Mwampamba, T. H., and Garcia-Frapolli, E. (2018). Uncovering links between livelihoods, land-use practices, vulnerability and forests after hurricane Jova in Jalisco, Mexico. For. Ecol. Manag. 426, 27-38. doi: 10.1016/j.foreco.2017.10.009

Lin, T. C., Hamburg, S. P., Lin, K. C., Wang, L. J., Chang, C. T., Hsia, Y. J., et al. (2011). Typhoon Disturbance and Forest Dynamics: Lessons from a Northwest Pacific Subtropical Forest. Ecosystems 14, 127-143. doi: 10.1007/s10021-0109399-1

Lin, T. C., Hogan, J. A., and Chang, C. T. (2020). Tropical cyclone ecology: A scalelink perspective. Trends Ecol. Evol. 35, 594-604. doi: 10.1016/j.tree.2020.02. 012

Lomáscolo, T., and Aide, T. M. (2001). Seed and seedling bank dynamics in secondary forests following hurricane Georges in Puerto Rico. Caribb. J. Sci. 37, 259-270. 
López-Marrero, T., Heartsill-Scalley, T., Rivera-López, C. F., Escalera-García, I. A., and Echevarría-Ramos, M. (2019). Broadening our understanding hurricanes and forests in the Caribbean island of Puerto Rico: Where and what should we study now? Forests 10:710. doi: 10.3390/f10090710

López-Marrero, T., and Castro-Rivera, A. (2020). Actividad Ciclónica en Puerto Rico y sus Alrededores: 1867 al 2020. Centro Interdisciplinario de Estudios del Litoral. Puerto Rico: Universidad de Puerto Rico.

Lugo, A. E. (2008). Visible and invisible effects of hurricanes on forest ecosystems: An international review. Austral Ecol. 33, 368-398. doi: 10.1111/j.1442-9993. 2008.01894.x

Lugo, A. E. (2020). Effects of Extreme Disturbance Events: From Ecesis to SocialEcological-Technological Systems. Ecosystems 23, 1726-1747. doi: 10.1007/ s10021-020-00491-x

Lugo, A. E., Abelleira-Martínez, O. J., Medina, E., Aymard, G., and HeartsillScalley, T. (2020). Novelty in the tropical forests of the 21 st century. Adv. Ecol. Res. 62, 53-116. doi: 10.1016/bs.aecr.2020.01.008

Lugo, A. E., Helmer, E. H., and Santiago Valentín, E. (2012). Caribbean landscapes and their biodiversity. Interciencia 37, 705-710.

Luke, D., McLaren, K., and Wilson, B. (2016). Modeling Hurricane Exposure in a Caribbean Lower Montane Tropical Wet Forest: The Effects of Frequent, Intermediate Disturbances and Topography on Forest Structural Dynamics and Composition. Ecosystems 19, 1178-1195. doi: 10.1007/s10021-016-9993-y

Martínez, C., Goddard, L., Kushnir, Y., Martinez, C., and Ting, M. (2019). Seasonal Climatology and Dynamical Mechanisms of Rainfall in the Caribbean. Clim. Dyn. 53, 825-846. doi: 10.1007/s00382-019-04616-4

Mascaro, J., Perfecto, I., Barros, O., Boucher, D. H., De La Cerda, I. G., Ruiz, J., et al. (2005). Aboveground Biomass Accumulation in a Tropical Wet Forest in Nicaragua Following a Catastrophic Hurricane Disturbance. Biotropica 37, 600-608. doi: 10.1111/j.1744-7429.2005.00077.x

McLaren, K., Luke, D., Tanner, E., Bellingham, P. J., and Healey, J. R. (2019). Reconstructing the effects of hurricanes over 155 years on the structure and diversity of trees in two tropical montane rainforests in Jamaica. Agric. For. Meteorol. 276:107621. doi: 10.1016/j.agrformet.2019.107621

McLean, N. M., Stephenson, T. S., Taylor, M. A., and Campbell, J. D. (2015). Characterization of Future Caribbean Rainfall and Temperature Extremes Across Rainfall Zones. Adv. Meteorol. 2015:425987. doi: 10.1155/2015/425987

Meléndez-Ackerman, E., Calisto-Pérez, C., Morales-Vargas, M., and FumeroCabán, J. (2003). Post-hurricane recovery of a herbaceous understory plant in a tropical rain forest in Puerto Rico. J. Trop. Ecol. 19, 677-684. doi: 10.1017/ s0266467403006072

Pagán-Jiménez, J. R., Rodríguez Ramos, R., and Hofman, C. L. (2019). "On the way to the islands: The role of domestic plants in the initial peopling of the Antilles" in Early Settlers of the Insular Caribbean: Dearchizing the Archaic. eds C. Holman and A. Antzcak (Netherlands: Sidestone Press), 89-106.

Perfecto, I., Hajian-Forooshani, Z., Iverson, A., Irizarry, A. D., Lugo-Perez, J., Medina, N., et al. (2019). Response of coffee farms to Hurricane Maria: Resistance and resilience from an extreme climatic event. Sci. Rep. 9, 1-11. doi: 10.1007/978-3-030-02387-4_1

Pruitt, J. N., Little, A. G., Majumdar, S. J., Schoener, T. W., and Fisher, D. N. (2019). Call-to-action: A global consortium for tropical cyclone ecology. Trends Ecol. Evol. 34, 588-590. doi: 10.1016/j.tree.2019.04.009

Rodríguez-Cruz, L. A., and Niles, M. T. (2021). Awareness of climate change's impacts and motivation to adapt are not enough to drive action: A look of Puerto Rican farmers after Hurricane Maria. PLoS One 16:e0244512. doi: 10. 1371/journal.pone.0244512

Royo, A. A., Heartsill-Scalley, T., Moya, S., and Scatena, F. N. (2011). Nonarborescent vegetation trajectories following repeated hurricane disturbance: ephemeral versus enduring responses. Ecosphere 2:77.

Sato, T. (2004). Litterfall dynamics after a typhoon disturbance in a Castanopsis cuspidate coppice, southwestern Japan. Ann. For. Sci. 61, 431-438. doi: 10.1051/ forest:2004036
Schowalter, T. D., Pandey, M., Presley, S. J., Willig, M. R., and Zimmerman, J. K. (2021). Arthropods are not declining but are responsive to disturbance in the Luquillo Experimental Forest. Puerto Rico. PNAS 118:e2002556117. doi: 10.1073/pnas.2002556117

Shiels, A. B., González, G., and Willig, M. R. (2014). Responses to canopy loss and debris deposition in a tropical forest ecosystem: Synthesis from an experimental manipulation simulating effects of hurricane disturbance. For. Ecol. Manag. 332, 124-133. doi: 10.1016/j.foreco.2014.08.005

Soto-Parrilla, N., and Heartsill-Scalley, T. (2021). Missing the Trees for the Forest: Post-Hurricane Understory Vegetation in Relation to Spatial Variation. Acta Cient.32, 44-54.

Stennett-Brown, R. K., Jones, J. J., Stephenson, T. S., and Taylor, M. A. (2017). Future Caribbean Temperature and Rainfall Extremes from Statistical Downscaling. Int. J. Climatol. 37, 4828-4845. doi: 10.1002/joc.5126

Torres, R., and Tsimplis, M. N. (2014). Sea level extremes in the Caribbean Sea. J. Geophys. Res. Oceans 119, 4714-4731. doi: 10.1002/2014jc009929

Torres-Martínez, E., Meléndez-Ackerman, E. J., and Trujillo-Pinto, A. (2021). Drivers of hurricane structural effects and mortality for urban trees in a community of San Juan. Puerto Rico. Acta Cient. 32, 33-43.

Uriarte, M., Thompson, J., and Zimmerman, J. K. (2019). Hurricane María tripled stem breaks and doubled tree mortality relative to other major storms. Nat. Commun. 10:1362. doi: 10.1038/s41467-019-09319-2

Wunderle, J. R. (1999). Pre-and post-hurricane fruit availability: Implications for Puerto Rican parrots in the Luquillo Mountains. Caribb. J. Sci. 35, 249-264.

$\mathrm{Xi}, \mathrm{W}$. (2015). Synergistic effects of tropical cyclones on forest ecosystems: a global synthesis. J. For. Res. 26, 1-21. doi: 10.1007/s11676-015-0018-z

Yaffar, D., and Norby, R. J. (2020). A historical and comparative review of 50 years of root data collection in Puerto Rico. Biotropica 52, 563-576. doi: 10.1111/btp. 12771

Yap, S. L., Davies, S. J., and Condit, R. (2016). Dynamic response of a Philippine dipterocarp forest to typhoon disturbance. J. Veg. Sci. 27, 133-143. doi: 10. $1111 /$ jvs. 12358

Yu, M., and Gao, Q. (2020). Topography, drainage capability, and legacy of drought differentiate tropical ecosystem response to and recovery from major hurricanes. Environ. Res. Lett. 15:104046. doi: 10.1088/1748-9326/abae2c

Yu, M., Rivera-Ocasio, E., Heartsill-Scalley, T., Davila-Casanova, D., Rios-López, N., and Gao, Q. (2019). Landscape-level consequences of rising sea-level on coastal wetlands: saltwater intrusion drives displacement and mortality in the twenty-first century. Wetlands 39, 1343-1355. doi: 10.1007/s13157-019-0 1138-x

Zimmerman, J. K., Wood, T. E., González, G., Ramirez, A., Silver, W. L., Uriarte, M., et al. (2021). Disturbance and resilience in the Luquillo Experimental Forest. Biolo. Conserv. 253:108891. doi: 10.1016/j.biocon.2020.1 08891

Conflict of Interest: The authors declare that the research was conducted in the absence of any commercial or financial relationships that could be construed as a potential conflict of interest.

Publisher's Note: All claims expressed in this article are solely those of the authors and do not necessarily represent those of their affiliated organizations, or those of the publisher, the editors and the reviewers. Any product that may be evaluated in this article, or claim that may be made by its manufacturer, is not guaranteed or endorsed by the publisher.

Copyright (C) 2021 Heartsill-Scalley and López-Marrero. This is an open-access article distributed under the terms of the Creative Commons Attribution License (CC BY). The use, distribution or reproduction in other forums is permitted, provided the original author(s) and the copyright owner(s) are credited and that the original publication in this journal is cited, in accordance with accepted academic practice. No use, distribution or reproduction is permitted which does not comply with these terms. 